\title{
Analysis of baseflow index based hydrological model in Upper Wei River basin on the Loess Plateau in China
}

\author{
DENGFENG LIU1 ${ }^{1}$, JIANXIA CHANG ${ }^{1}$, FUQIANG TIAN ${ }^{2}$, QIANG HUANG ${ }^{1} \&$ \\ XIANMENG MENG ${ }^{3}$
}

1 State Key Laboratory Base of Eco-hydraulic Engineering in Arid Areas, School of Water Resources and Hydropower, Xi'an University of Technology, Xi'an, 710048, China liudf@xaut.edu.cn

2 State Key Laboratory of Hydroscience and Engineering, Department of Hydraulic Engineering, Tsinghua University, Beijing, 100084, China

3 School of Environmental Studies, China University of Geosciences, Wuhan, 430074, China

\begin{abstract}
The baseflow is the drainage from the groundwater and soil water to the streamflow. As one important source of the streamflow, the baseflow could be the main source of the streamflow in the dry season. The Wei River, located in the semi-arid region of the Loess Plateau which is overlain by deep and loose soil, is the largest tributary of the Yellow River. According to former research, most of the streamflow in the dry season in the headwater of the Yellow River is baseflow. For the whole Yellow River basin, the baseflow is an important component of the streamflow, and accounts for about $44 \%$ of the annual runoff. Physically-based distributed hydrological models can simulate the runoff components separately, and are important tools to analyse the runoff components. Given the importance of the baseflow in the dry season for drought relief to support the ecological water requirement and irrigation, especially in the Wei River, the baseflow is analysed in this study. To investigate the baseflow in the Upper Wei River basin, a semidistributed hydrological model based on a Representative Elementary Watershed approach (THREW) is employed to investigate the runoff generation process. To compare the results, an automatic baseflow separation method proposed by Arnold is used to separate the baseflow from the daily streamflow at Beidao hydrological station in Upper Wei River basin from 2001 to 2004. Based on the hydrological modelling and the Arnold separation method, the average annual baseflow index, i.e. the ratio of baseflow to the total runoff, is estimated as in the range of 0.30-0.36. The average intra-annual monthly baseflow index represents the seasonality of the baseflow due to the seasonality of the precipitation and evapotranspiration, and is also analysed.
\end{abstract}

Key words baseflow, hydrological model, Wei River basin, Loess Plateau

\section{INTRODUCTION}

Baseflow is considered to be the groundwater contribution to streamflow (Arnold et al., 1995) and is one important component of the runoff in a river, especially in arid and semi-arid regions. The Wei River is located in the semi-arid region of the Yellow River basin in China. Due to the increase of the water withdrawal to supply agricultural irrigation and urban water consumption in Shaanxi, which is in the lower reach of the Wei River basin, baseflow is playing a more and more important role to satisfy the instream ecological water demand in the Wei River. According to research, most of the streamflow in the dry season in the headwaters of the Yellow River is the baseflow (Chen et al., 2006). Even for the whole Yellow River basin, the baseflow is an important component of the streamflow, and accounts for about $44 \%$ of the annual runoff (Wang et al., 2008). The quantification of the baseflow in the Wei River is an interesting topic.

The traditional method to separate the baseflow is to analyse the discharge records (Arnold et al., 1995; Aksoy et al., 2009; Wang and Cai, 2010). At the same time, a distributed physicallybased distributed hydrological model could simulate the runoff components separately, and could be another option to analyse the runoff components. Previous hydrological modelling (Liu et al., 2012) has shown some results about the proportion of the baseflow in the Upper Wei River. Given the importance of the baseflow in the dry season for drought relief to support the ecological water requirement and irrigation, especially in the Wei River, the baseflow is analysed using a distributed physically-based hydrological model and baseflow separation method. 


\section{STUDY AREA AND DATA}

The Wei River, located in the semi-arid region of Loess Plateau which is overlain by deep and loose soil, is the largest tributary of the Yellow River. The study area is the upstream of Beidao hydrological station $\left(105.905^{\circ} \mathrm{E}, 34.569^{\circ} \mathrm{N}\right)$ in the Wei River basin and it is hereafter denoted as Upper Wei River basin (UWRB). The drainage area of UWRB is about $24800 \mathrm{~km}^{2}$. The mean annual precipitation is $512 \mathrm{~mm}$ and the mean annual potential evaporation is $893 \mathrm{~mm}$.

The data used in the study include DEM, soil data, leaf area index (LAI), fraction of vegetation cover, meteorological data and discharge data. The spatial resolution of the DEM is $84 \mathrm{~m} \times 84 \mathrm{~m}$ and the elevation of the UWRB is shown in Fig. 1. The soil data were obtained from the 1:1000 000 China Soil Database (from Institute of Soil Science, Chinese Academy of Sciences). LAI is extracted from MODIS/Terra Leaf Area Index/FPAR 8-Day L4 Global $1 \mathrm{~km}$ SIN Grid V005 (MOD15A25), and the fraction of vegetation cover comes from MODIS/Terra Vegetation Indices Monthly L3 Global $1 \mathrm{~km}$ SIN Grid V005 (MOD13A3). The meteorological data of 18 weather stations were obtained from the meteorological agency and the location of the rainfall stations are shown in Fig. 2. Daily discharge data at Beidao hydrological station from 2001 to 2004 were collected from the hydrological agency.

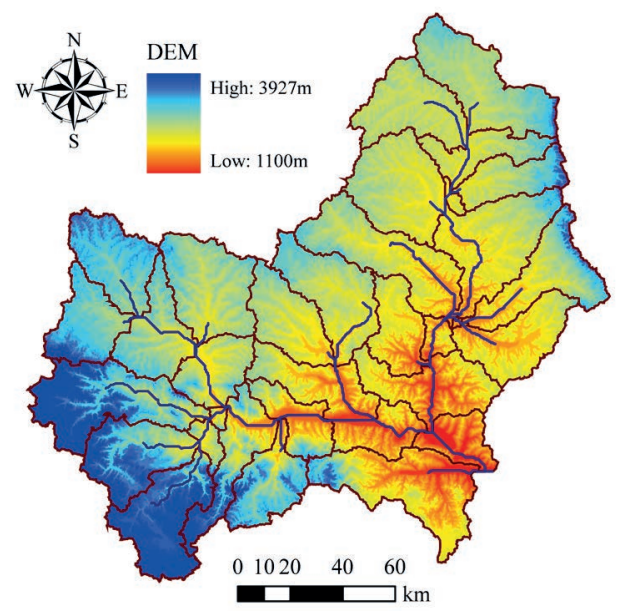

Fig. 1 The DEM of the Wei River Basin in China.

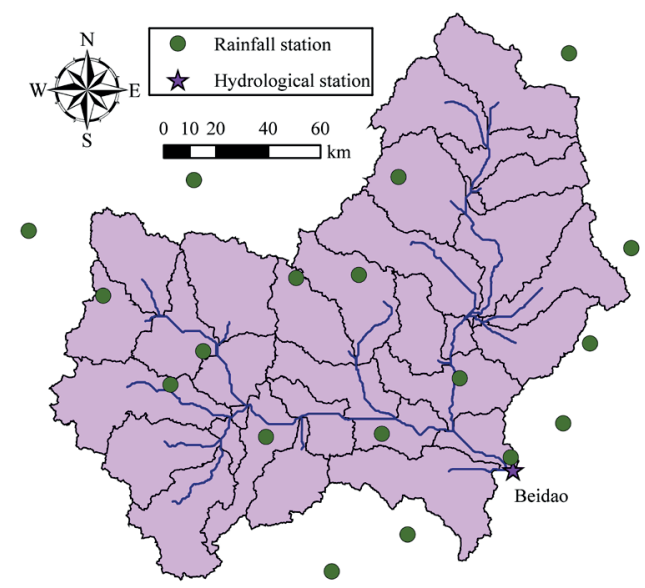

Fig. 2 Location of the rainfall stations and hydrological stations in the Wei River basin.

\section{HYDROLOGICAL MODEL}

The Tsinghua Hydrological Model based on REW (THREW model) is a semi-distributed physically-based hydrological model which uses Representative Elementary Watersheds (REWs) 
as the hydrological response unit. In THREW, each REW is subdivided into several sub-zones (Tian et al., 2006). There are the vegetated zone, bare soil zone, and main channel zone above the land surface, and the saturated zone and unsaturated zone under the land surface. For more details about THREW model, please refer to Tian et al. (2006).

After the development of THREW in 2006, it was successfully applied in many river basins, such as the Chabagou River basin of China (Tian, 2006), the headwaters of the Urumqi River, China (Mou et al., 2008), the Upper Sangamon River basin in Illinois State of USA (Liu et al., 2009; Li et al., 2010), the test watersheds in the Distributed Hydrologic Model Intercomparison Project - Phase 2 (DMIP2) (Li et al., 2012; Tian et al., 2012) and the Wei River Basin in China (Liu et al., 2012). The performance of THREW proved its ability to simulate the runoff component in the runoff generation process. In the model, four runoff components are simulated in the runoff generation processes: Hortonian runoff, Dunne runoff, quick subsurface flow, and slow subsurface flow. Hortonian runoff and Dunne runoff are surface runoff generated on the land surface during the rainfall. Quick subsurface flow and slow subsurface flow are the subsurface flow from the shallow soil layer and deep soil layer, respectively.

In the study, the Tsinghua Hydrological Model based on REW (THREW) is used to simulate the baseflow in the Upper Wei River basin. Based on the DEM of the Upper Wei River basin, the study area was divided into 35 sub-watersheds, i.e. Representative Elementary Watersheds (REWs) as shown in Fig. 1. The average area of the REWs is $708 \mathrm{~km}^{2}$. The daily meteorological data (precipitation and potential evaporation) of 18 weather stations within or adjacent to UWRB (Fig. 2) from 2001 to 2004 were interpolated using Tessellation Polygons. The THREW model was run at daily temporal resolution for the period from 2001 to 2004.

\section{BASEFLOW SEPARATION METHOD}

The methods to separate baseflow from the flow have been investigated by many researchers, such as Arnold et al. (1995), Aksoy et al. (2009), Wang and Cai (2010), and others. Arnold et al. (1995) developed an automated baseflow separation method using a digital filter and tested it against three other automated techniques and manual separation methods. Since then the automated baseflow separation method has been widely used to separate baseflow from the streamflow. Aksoy et al. (2009) coupled the smoothed minima baseflow separation method of the United Kingdom Institute of Hydrology (UKIH) with the recursive digital filter (RDF) to develop the filtered smoothed minima baseflow separation (FUKIH) method, in which a smooth hydrograph representing the baseflow generating mechanisms is obtained. Wang and Cai (2010) provided an analytical baseflow recession equation to discuss the impact of human interferences, which include groundwater pumping, water diversion and return flow, on the determination of the recession slope curve. In the study, the automatic baseflow separation method proposed by Arnold et al. (1995) (hereafter noted as Arnold separation method) is used to separate the baseflow of the daily streamflow at Beidao hydrological station in Upper Wei River basin from 2001 to 2004. The baseflow index is defined as the ratio of the baseflow to the total runoff. With the daily baseflow from the Arnold separation method, the average intra-annual monthly baseflow index and annual baseflow index are calculated.

\section{RESULTS}

The THREW model for the Upper Wei River basin in China was calibrated and evaluated by Liu et al. (2012). The Nash-Sutcliffe efficiency coefficient (NSEC) and the coefficient of determination $\left(R^{2}\right)$ were applied to evaluate the performance of the model quantitatively. In the simulation period of 2001-2004, NSEC reached 0.63 and $R^{2}$ reached 0.65 for the total period of 2001-2004. The hydrograph of the simulation period in the Upper Wei River basin was shown in Liu et al. (2012). As the continuous hydrological model for the semi-arid region, THREW has a reasonable performance in modelling the rainfall-runoff process in the Upper Wei River basin.

In the THREW model, fast subsurface flow can quickly respond to the change of the water storage in the upper soil layer due to rainfall infiltration, and more or less represents the interflow 
in the upper layer soil near the river channel (Liu et al., 2012). The slow subsurface flow is the outflow of the groundwater. The baseflow consists of the fast subsurface flow and slow subsurface flow in the modelling.

\section{Annual baseflow index}

The result of the modelling shows that the max annual baseflow index is 0.460 in 2003 and the min annual baseflow index is 0.184 in 2002 . The average annual baseflow index from the THREW model is 0.303 , as shown in Table 1 .

The baseflow at the Beidao Station from Arnold separation method is shown in Fig. 3, and annual baseflow index from the Arnold separation method is shown in Table 1. The average annual baseflow index is 0.360 . The baseflow index from THREW is close to that from the Arnold separation method. The baseflow separation from the hydrological model is based on the runoff generation processes and the baseflow separation from the traditional baseflow separation method is based on the hydrograph at the outlet of the watershed with some assumptions. So the baseflow index from the hydrological model and traditional baseflow separation method may be a bit different. Based on the baseflow index from THREW and the Arnold separation method, the average annual baseflow index in Upper Wei River basin is in the range of $0.30-0.36$.

Table 1 The comparison of annual baseflow index.

\begin{tabular}{lll}
\hline Period & THREW model & Arnold separation method \\
\hline 2001 & 0.248 & 0.347 \\
2002 & 0.184 & 0.271 \\
2003 & 0.460 & 0.367 \\
2004 & 0.322 & 0.457 \\
Average & 0.303 & 0.360 \\
\hline
\end{tabular}

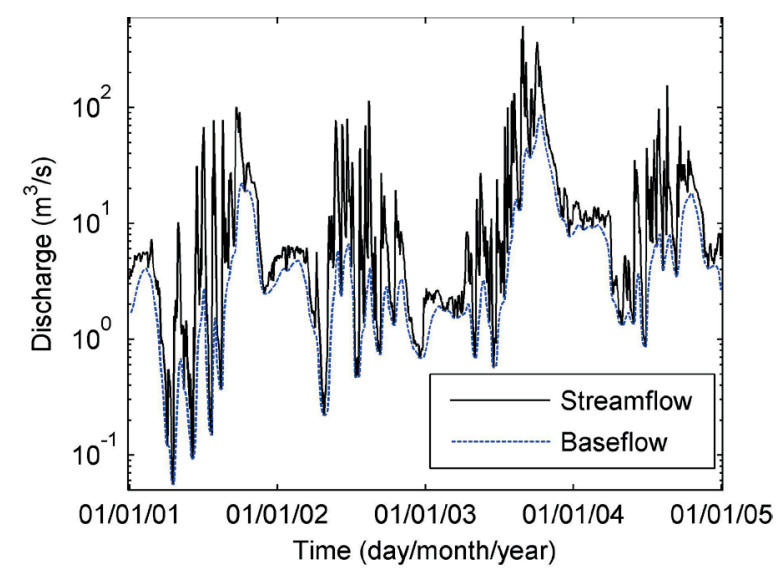

Fig. 3 The hydrograph of the streamflow and the baseflow from the Arnold separation method.

In the upstream of Tangnaihai station in Yellow River, Chen et al. (2006) found that the average annual baseflow index is 0.652 based on the streamflow data from 1956 to 2000 . Compared with the upstream of Tangnaihai station in the Yellow River, the baseflow index in the Upper Wei River is smaller and the drainage to the streamflow is less. Qian et al. (2004) analysed the baseflow index of seven rivers in the middle reach of Yellow River, all of which are on the Loess Plateau, and found that the average baseflow index of the seven rivers, i.e. Huangfu, Gushan, Qingjian, Kuye, Jialu, Wuding and Tuwei, was $0.11,0.18,0.29,0.33,0.40,0.55$ and 0.68 , respectively. It suggests that the annual baseflow indices of the rivers on the Loess Plateau are quite different because of the underlying conditions. The baseflow index of Upper Wei River basin 
is within the range of the baseflow index of the seven rivers and should be reasonable. In the future, the baseflow index will be investigated based on long-term discharge data.

\section{Monthly baseflow index}

The average intra-annual monthly baseflow index represents the seasonality of the baseflow due to the seasonality of precipitation and evapotranspiration. The monthly baseflow index from the hydrological modeling is shown in Fig. 4. The monthly baseflow index from April to September is in the range $0.065-0.276$, and that is in the range 0.527-0.893 from October to March of the next year, when the main source of the streamflow is the baseflow. The maximum is 0.893 in December and the minimum is 0.065 in July. From October to March, the subsurface flow, i.e. the sum of the fast subsurface flow and the slow subsurface flow, dominates the runoff with a proportion of more than 53\%, and more than 69\% from November to February, especially. Dunnian runoff still dominates the runoff from April to September with the proportion of more than $72 \%$.

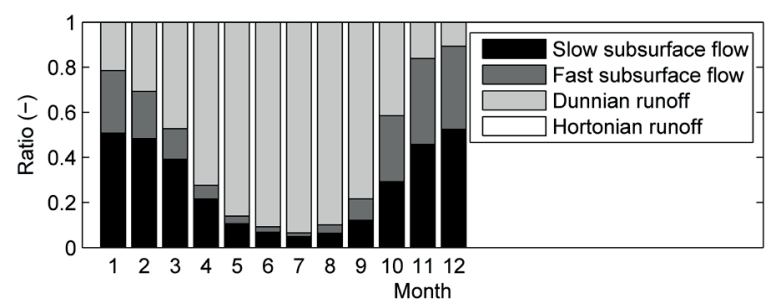

Fig. 4 The monthly ratio of the subsurface flow to the streamflow from THREW model.

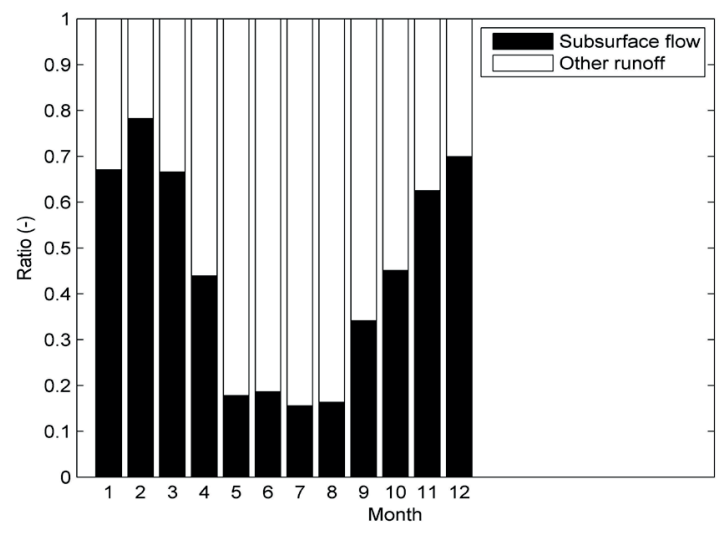

Fig. 5 The monthly ratio of the subsurface flow to the streamflow from Arnold separation method.

The monthly baseflow index calculated by the Arnold separation method is shown in Fig. 5. The monthly baseflow index from October to March is in the range of 0.451-0.782. From April to September, the baseflow index is $0.155-0.439$, larger values than that from hydrological modeling. The maximum is 0.782 in February and the minimum is 0.155 in July.

The baseflow index from Arnold separation method has a similar pattern to the baseflow index from THREW model, as shown in Figs 4 and 5. The minimum monthly baseflow index is in July. The index from May to August is markedly smaller than that of other months, in the range $0.065-0.140$ from hydrological modeling and $0.155-0.186$ from the Arnold separation method. The result of the two methods shows that, the main source of the streamflow is the baseflow from October to March. The monthly baseflow index for November to March is in the range $0.527-0.893$ and $0.625-0.782$ from hydrological modeling and the Arnold separation method, respectively. The results suggest that the dominant runoff generation mechanism is different in different months and the subsurface flow dominates the runoff generation processes from November to March. 


\section{CONCLUSION}

Given the importance of baseflow in dry season for drought relief to support the ecological water requirement and irrigation, especially in the Wei River, the baseflow was analysed. To investigate the baseflow in the Upper Wei River basin, a semi-distributed hydrological model based on the Representative Elementary Watershed approach (THREW) was employed to investigate the runoff generation process. To compare the result, an automatic baseflow separation method proposed by Arnold was used to separate the baseflow of the daily streamflow at Beidao hydrological station in Upper Wei River basin from 2001 to 2004.

Based on the hydrological modelling and the Arnold separation method, the average annual baseflow index, i.e. the ratio of baseflow to the total runoff, is estimated as approximately in the range $0.30-0.36$. The average intra-annual monthly baseflow index represents the seasonality of the baseflow due to the seasonality of the precipitation and the evapotranspiration, and was also analysed. The hydrological modelling shows that, the monthly baseflow index from April to September is in the range 0.065-0.276, and in the range 0.527-0.893 from October to March of the next year. From the results of the Arnold separation method, the monthly baseflow index from April to September is in the range of 0.155-0.439, and t 0.451-0.782 from October to March of the next year. The monthly baseflow index from May to August is $0.065-0.140$ from the hydrological modelling and $0.155-0.186$ from the Arnold separation method, very small values.

In the study, the 4-years discharge data are used and in the future, the baseflow index will be investigated based on long-term discharge data and other baseflow separation methods will be applied.

Acknowledgements This work is supported by the National Natural Science Foundation of China (Grant No. 51309188, 51190093 and 51190092). The funding also comes from SRFDP (20136118120021) and Key Innovation Group of Science and Technology of Shaanxi (2012KCT10). The financial support is greatly appreciated.

\section{REFERENCES}

Aksoy, H., Kurt, I. and Eris, E. (2009) Filtered smoothed minima baseflow separation method. Journal of Hydrology 372(1-4), 94-101.

Arnold, J. G., et al. (1995) Automated base flow separation and recession analysis techniques. Ground Water 33(6), 1010-1018. Chen, L., et al. (2006) Baseflow estimation of the source regions of the Yellow River. Geographical Research (04), 659-665.

Li, H., et al. (2010) Water and nutrient balances in a large tile-drained agricultural catchment: a distributed modeling study. Hydrology and Earth System Sciences 14(11), 2259-2275.

Li, H., Sivapalan, M. and Tian, F. (2012) Comparative diagnostic analysis of runoff generation processes in Oklahoma DMIP2 basins: The Blue River and the Illinois River. Journal of Hydrology 418-419(0), 90-109.

Liu, D., et al. (2012) The role of run-on for overland flow and the characteristics of runoff generation in the Loess Plateau, China. Hydrological Sciences Journal 57 (6), 1107-1117.

Liu, D., Tian, F. and Hu, H. (2009) Sediment simulation at Upper Sangamon River basin using THREW model. In: Hydrological Modelling and Integrated Water Resources Management in Ungauged Mountainous Watersheds (ed. by Wei-Lin Xu et al.). IAHS Publ. 335, 187-195.

Mou, L., et al. (2008) Extension of the Representative Elementary Watershed approach for cold regions: constitutive relationships and an application. Hydrology and Earth System Sciences 12(2), 565-585.

Qian, Y., et al. (2004) Analysis on the characteristic and variation of base flow in loessial plateau of the middle reaches of Huanghe River. Journal of Earth Sciences and Environment (02), 88-91.

Tian, F. (2006) Study on thermodynamic watershed hydrological model (THModel) (Dissertation). Beijing. China: Tsinghua University.

Tian, F., et al. (2006) Extension of the representative elementary watershed approach for cold regions via explicit treatment of energy related processes, Hydrology and Earth System Science 10, 619-644.

Tian, F, Li, H. and Sivapalan, M. (2012) Model diagnostic analysis of seasonal switching of runoff generation mechanisms in the Blue River basin, Oklahoma. Journal of Hydrology 418-419(0), 136-149.

Wang, D. and Cai, X. (2010) Recession slope curve analysis under human interferences. Advances in Water Resources 33(9), $1053-1061$.

Wang, Y., et al. (2008) Change characteristics and driving forces of base flow of Yellow River basin. Journal of Natural Resources 23(3), 479-486. 